\title{
Body composition predicted from skinfolds in African women: a cross-validation study using air-displacement plethysmography and a black-specific equation
}

\author{
Aïssatou Dioum ${ }^{1}$, Agnès Gartner ${ }^{2} *$ Bernard Maire $^{2}$, Francis Delpeuch $^{2}$ and Salimata Wade ${ }^{1}$ \\ ${ }^{1}$ Equipe de Nutrition, Laboratoire de Physiologie, Département de Biologie Animale, Faculté des Sciences et Techniques, Université \\ Cheikh Anta Diop de Dakar, Sénégal, West Africa \\ ${ }^{2}$ Nutrition Unit, UR 106 (WHO Collaborating Centre for Nutrition), IRD (Institut de Recherche pour le Développement), BP 64501, \\ 911 Avenue Agropolis, 34394 Montpellier Cedex 5, France
}

(Received 9 June 2004 - Revised 2 December 2004 - Accepted 11 January 2005)

\begin{abstract}
Skinfold thickness (SF) measurements are commonly used for the indirect assessment of body composition. It is necessary to know how large the bias is when using Caucasian SF-based prediction equations Africans, as no specific equations exist. Our first aim was to test the validity of the equation of Durnin \& Womersley for predicting body density from SF in Africans. The second aim was to determine the effect of calculating percentage body fat (\%BF) from body density using a black-specific formula rather than the Siri equation, thus taking into account the higher fat-free mass (FFM) density in blacks than in whites. A total of 196 African women volunteered. Mean age was 29.5 (SD 8.7) years and mean BMI was 22.5 (SD 4.6 ) $\mathrm{kg} / \mathrm{m}^{2}$. We compared body density values predicted from SF with those measured by air-displacement plethysmography, and \%BF values obtained from body density using the Siri equation or the black-specific calculation. The bias (reference minus prediction) was $0.0100 \mathrm{~kg} / \mathrm{cm}^{3}$ in body density $\left(P<10^{-4}\right)$ and $6.5 \% \mathrm{BF}\left(P<10^{-4}\right)$, and the error (SD of the bias) $0.0097 \mathrm{~kg} / \mathrm{l}$ and $4.5 \% \mathrm{BF}$. With the black-specific equation, the bias was reduced by $1.9 \% \mathrm{BF}$, while error remained similar. As the \%BF prediction required an SF-based equation followed by a body density-based calculation, the lack of validity we observed in Africans may be due to known differences between blacks and whites in the distribution of subcutaneous adipose tissue and, as demonstrated, in the FFM density. Equations thus need to be established using SF values specific to Africans.
\end{abstract}

Skinfold thickness: Fat prediction equations: African women

Body composition is an important indicator of an individual's health and nutritional status. Many methods and techniques for estimating body composition have been developed over the years (Lukaski, 1987; Deurenberg, 1992; Roche et al. 1996). Cheap and simple methods are needed for routine clinical and epidemiological field studies, and the most widely used method is anthropometry (Lohman et al. 1988), particularly the measurement of skinfold thickness (SF; Harrison et al. 1988). SF measurement is an indirect method that requires the use of a prediction equation established against a reference method, assuming that there is no difference in the distribution of subcutaneous fat across groups of subjects (Lukaski, 1987). However, it is well known that there are a number of differences in body composition between blacks and whites, such as fat patterning and fat distribution (Zillikens \& Conway, 1990) and the length of the limbs in relation to the trunk (Wagner \& Heyward, 2000). In addition, blacks have a greater bone mineral density and body protein content than do whites, resulting in a higher density of fat-free mass (FFM; Ortiz et al. 1992; Wagner \& Heyward, 2000). This calls into question the usefulness of the Caucasian equations to predict percentage body fat $(\% \mathrm{BF})$ from SF in black African people, as has already been demonstrated in African-American subjects (Zillikens \& Conway, 1990; Brandon, 1998) and in Asians (Deurenberg \& Deurenberg-Yap, 2003). Although skinfold equations have been used for several years, their accuracy in Africans has not been determined, except in a pilot study in South Africa (Oosthuizen et al. 1997) and a recent study in African children (Cameron et al. 2004).

The equation of Durnin \& Womersley (D\&W) (1974) can be used to transform the measurement of SF into body density values. It has been established in a Caucasian sample against hydrodensitometry (HD). The D\&W equation is valid in Caucasians (Going, 1996) but has not always proved valid in other ethnic groups. The first aim of the present study was to assess the validity of the prediction of body density from SF in black African women using the D\&W equation compared with air-displacement plethysmography (ADP) measurement as one possible reference method in situ. \%BF is usually calculated from body density using the Siri equation (1961), which assumes the density of FFM to be constant. The second aim of the study was to

Abbreviations: ADP, air-displacement plethysmography; \%BF, percentage body fat; D\&W, Durnin \& Womersley; FFM, fat-free mass; HD, hydrodensitometry; SF, skinfold thickness; TGV, thoracic gas volume.

* Corresponding author: Dr A. Gartner, fax +334674163 30, email gartner@mpl.ird.fr 
estimate the effect of using a specifically adapted equation for black subjects when calculating \% BF from body density in comparison with the Siri equation (1961).

\section{Subjects and methods}

\section{Subjects}

The sample included 196 women who were recruited from the community in a peri-urban neighbourhood of Dakar, the capital city of Senegal (West Africa). The ethics committee of the University of Dakar approved the study. All subjects gave their written consent to participate in the study after being thoroughly informed of its purpose, requirements and procedures. All measurements were performed at the IRD Centre of Dakar. Subjects fasted from food and drink for at least $6 \mathrm{~h}$ and emptied their bladder preceding the measurements. Anthropometry and ADP measurements were performed the same morning and applied to each subject in random order.

\section{Anthropometry}

Measurements were made by trained personnel using standard procedures (Lohman et al. 1988). The subject's body weight was measured during the ADP measurement procedure (see later). Height was measured to the nearest millimetre with a portable gauge (Seca Weighing and Measuring Systems, Hamburg, Germany). The four BMI classes, i.e. thin, normal, overweight and obese, were defined by using the BMI thresholds of 18.5 , 25 and $30 \mathrm{~kg} / \mathrm{m}^{2}$. Sitting height was measured to the nearest millimetre using the gauge while the subject was sitting on a stool. The height of the stool was subtracted from the measurement. Leg length was calculated as height minus sitting height. Relative leg length was calculated as leg length divided by height $(\mathrm{cm} /$ $\mathrm{cm})$. All circumferences were measured to the nearest $0.1 \mathrm{~cm}$ with a non-elastic metric measuring tape. The left mid-upper arm circumference was measured at the midpoint of the upper arm with the subject's arm relaxed. For measurement of the hip circumference, the measurer squatted beside the subject to judge the level of maximum extension of the buttocks. The circumference was measured at this level on a horizontal plane. Waist circumference was measured on a horizontal plane at the narrowest part of the torso (i.e. the smallest horizontal circumference in the area between the ribs and iliac crest). SF measurements were made on the left side of the body using a Holtain (Holtain Ltd, Crosswell, Crymmych, Dyfed, Wales, UK) skinfold calliper. The measurements were made to the nearest millimetre at the triceps, biceps, subscapular and suprailiac sites in each woman. Anthropometric measurement values were the mean of duplicates. The SF ratio was calculated as the sum of subscapular + suprailiac divided by the sum of triceps + biceps. All measurements were made by the same observer (A.G.) to avoid any systematic technical bias.

\section{Reference method: air-displacement plethysmography}

ADP is a new practical alternative reference method (Dempster \& Aitkens, 1995; McCrory et al. 1995; Biaggi et al. 1999; Nunez et al. 1999; Fields et al. 2002). ADP is a reliable and valid technique that can quickly and safely evaluate body volume (Demerath et al. 2002; Fields et al. 2002). Whole-body density can therefore be determined from body volume and weight, and ADP agrees with $\mathrm{HD}$, which uses underwater weighing, within $1 \%$ BF in adults (Fields et al. 2002). ADP has the potential to replace $\mathrm{HD}$ as a standard of practice in research and clinical settings as it is less expensive, could be more easily available and can be performed in all subjects because (in contrast to HD) it is trouble-free for the subject.

In this study the ADP method used the BOD POD ${ }^{\mathrm{TM}}$ bodycomposition system (model 2000A; Life Measurement Instruments, Concord, CA, USA; software version 1.69, 19 June 1997). The device is a single egg-shaped unit consisting of two chambers: a test chamber where the subject is seated and a reference chamber with the breathing circuit. As described in detail (Dempster \& Aitkens, 1995), the system determines body volume by air displacement using Poisson's gas law (McCrory et al. 1995).

Wearing minimal clothing, subjects were first weighed to the nearest $0.01 \mathrm{~kg}$ using the $\mathrm{BOD} \mathrm{POD}^{\mathrm{TM}}$ system electronic scale (Tanita Corp., Tokyo, Japan). Since hair contributes to measurement error, subjects were required to wear an acrylic bathing cap. After a two-point calibration with the chamber empty and with a standard 50-litre cylinder in the test chamber, the volume of the subject was obtained while she was seated quietly in the test chamber and breathing normally. An average of two trials was used in estimating body volume. To correct for the volume of air exhaled by the subject (thoracic gas volume, $\mathrm{TGV}$ ) that comes into contact with the chamber gas volume during the body volume test, while in the test chamber and wearing nose clips the subject was instructed to perform a gentle "puffing' manoeuvre against a momentarily occluded airway. During this brief procedure, the subject breathed through disposable tubing that was connected to a pulmonary function analyser and then quickly alternated between contraction and relaxation of the diaphragm. The adjusted body volume and the subject's body weight were used to calculate body density. A predicted, rather than measured, value for the TGV can be used that is calculated by a formula (kept secret by the manufacturer) using height and age. In thirty-eight of the 196 subjects, TGV was not adequately measured, so predicted TGV was used. The difference between using measured or predicted TGV was previously studied in 114 women (Gartner et al. 2004).

\section{Body composition calculation}

From air-displacement plethysmography. As we reported in previous studies in Senegalese women (Gartner et al. 2003, 2004), $\% \mathrm{BF}_{\mathrm{ADP}}$ was calculated from body density $\mathrm{ADP}_{\mathrm{AP}}$ by taking into account the value of $1 \cdot 106 \mathrm{~kg} / \mathrm{cm}^{3}$ given by Ortiz et al. (1992) for the density of FFM in black women and the value of $0.9007 \mathrm{~kg} /$ $\mathrm{cm}^{3}$ for the density of fat used in black men by Wagner \& Heyward (2000). The precise equation that we established (Gartner et al. 2004) is:

$$
\% \mathrm{BF}_{\mathrm{ADP}}=[(4 \cdot 852285436 / \text { body density } \mathrm{ADP})-4 \cdot 387238188]
$$

$$
\times 100 \text {. }
$$

$\mathrm{FFM}_{\mathrm{ADP}}$ was estimated by calculating body weight minus body fat mass.

From skinfold-thickness measurements. Density was predicted from the sum of four SF at the triceps, biceps, subscapular and suprailiac sites by using the D\&W equations: 
Age $<20$ years:

body density ${ }_{\mathrm{DW}}=1.1549-0.0678 \times \log (\operatorname{sum} 4 \mathrm{SF})$,

Age 20-29 years:

body density $_{\mathrm{DW}}=1.1599-0.0717 \times \log (\operatorname{sum} 4 \mathrm{SF})$,

Age 30-39 years:

body density DW $=1.1423-0.0632 \times \log (\operatorname{sum} 4 \mathrm{SF})$,

Age 40-49 years:

body density DW $=1.1333-0.0612 \times \log (\operatorname{sum} 4 \mathrm{SF})$,

Age $>49$ years:

body density DW $=1.1339-0.0645 \times \log (\operatorname{sum} 4 \mathrm{SF})$.

$\% \mathrm{BF}$ was calculated from this density by using the Siri (1961) equation $\left(\% \mathrm{BF}_{\mathrm{DWS}}\right)$ or by using the black-specific equation $\left(\% \mathrm{BF}_{\mathrm{DWB}}\right)$ (see earlier):

$$
\begin{aligned}
& \% \mathrm{BF}_{\mathrm{DWS}}=[(4 \cdot 95 / \text { body density } \\
& \text { DW }-4 \cdot 5] \times 100 \\
& \% \mathrm{BF}_{\mathrm{DWB}}= {[(4 \cdot 852285436 / \text { body density }} \\
& \times 100
\end{aligned}
$$

$\mathrm{FFM}_{\text {Dws }}$ or $\mathrm{FFM}_{\mathrm{DWB}}$ was estimated by calculating body weight minus the corresponding body fat mass.

\section{Statistical analysis}

Statistical software used for data entry and validation was Epi-Info (Centers for Disease Control and Prevention, Atlanta, GA, USA). Statistical analyses were performed using the SAS system for Windows (SAS Institute Inc., Cary, NC, USA), release 8.0. Values are expressed as means and standard deviations. First type error risk was set at 0.05 for all analyses. Intra-subject reliability was tested by performing duplicates. Intra-subject differences were calculated in absolute values. The technical error of measurement $\left(\mathrm{TEM}=\sqrt{\sum(\text { intra-subject difference })^{2}} / 2 \times\right.$ number of duplicates) and the percentage reliability $($ TEM $\times 100$ /overall mean of the measurements) were calculated. The difference between measured and predicted value (bias) was tested against zero (paired $t$ test). Considering the precision of the skinfold method and the biological plausibility of a variation in $\% \mathrm{BF}$, we considered that the smallest difference worth indicating a lack of validity of the skinfold method is about $1 \% \mathrm{BF}$. According to more recent studies assessing the validity of skinfold equations in the prediction of $\% \mathrm{BF}$, the expected standard deviation of the bias between a reference method and the skinfold method should be in the 3-5\% range. With 196 subjects there was sufficient power to look for bias, as our study power to detect a difference of $1 \%$ BF was $80-100 \%$ for an SD of $3-5 \%$. The dependence of the bias on the mean of measured and predicted values was tested using correlation analysis. The bias $95 \%$ limits of agreement, calculated as \pm 1.96 error (i.e. SD of the bias), were used to test agreement between the two methods (Bland \& Altman, 1986, 1995). The performance of the D\&W prediction equation when applied to a sample independent from the one used to construct the equation (cross-validation) was measured by the pure error (Guo et al. 1996). Pure error is calculated as the square root of the sum of squared differences between the observed and the predicted values divided by the number of subjects in the cross-validation sample. It summarizes the differences between observed and predicted values, and is mathematically the same as the standard error of estimate often used for precision. There is no criterion value for the pure error that indicates successful cross-validation, but the pure error should be similar to the precision value of the same equation from its validation in the population from which it is derived.

\section{Results}

Some characteristics of the 196 subjects are shown in Table 1. The data encompass a wide range of BMI and sum of four SF values. In our sample, the proportion of subjects with $\mathrm{BMI}<18.5 \mathrm{~kg} / \mathrm{m}^{2}$, with $25 \leq \mathrm{BMI}<30 \mathrm{~kg} / \mathrm{m}^{2}$ and with BMI $\geq 30 \mathrm{~kg} / \mathrm{m}^{2}$ was respectively $21.7 \%, 24.2 \%$ and $5.6 \%$. Table 1 also presents different anthropometric characteristics.

The intra-subject reliability of biceps, triceps, suprailiac and subscapular SF measurements was estimated. Absolute values of the difference between replicates of these SF ranged from 0 to $3 \cdot 1$, from 0 to 3.8 , from 0 to 4.8 and from 0 to $3.7 \mathrm{~mm}$, respectively. The percentage of reliability varied between sites of SF measurement but was always good $(6 \cdot 2,3 \cdot 5,5 \cdot 0$ and $4 \cdot 0$, respectively). The intra-subject reliability of ADP was previously reported in 128 subjects (Gartner et al. 2004) showing a percentage reliability of 1.3 for FFM and 2.4 for $\%$ BF when using a constant lung volume.

Table 2 shows body density ${ }_{\mathrm{ADP}}, \% \mathrm{BF}_{\mathrm{ADP}}$ and $\mathrm{FFM}_{\mathrm{ADP}}$ and values predicted from body density $\mathrm{DW}_{\mathrm{DW}}$ by using the Siri (1961) equation or the black-specific equation, respectively. The comparisons between reference and predicted values are shown in Table 3. For all the comparisons, the biases were significant (Table 3). The D\&W equation overestimated body density by about $0.01 \mathrm{~kg} / \mathrm{cm}^{3}$; consequently, $\% \mathrm{BF}$ was underestimated and FFM overestimated. The bias in $\% \mathrm{BF}$, as well as in FFM, was higher when using the Siri equation (1961) rather than the black-specific calculation; the difference in bias was about $1.9 \% \mathrm{BF}$ and $1.2 \mathrm{~kg}$ FFM. The significant biases resulted in large $95 \%$ limits of agreement for all the comparisons, yielding unacceptable potential bias at the level of the individual. When we segregated the women as a function of BMI, a significant bias was found in all the BMI groups (Table 4). Moreover, the higher the BMI value the higher was the bias value. There was

\begin{tabular}{|c|c|c|c|}
\hline & Mean & SD & $\begin{array}{l}\text { Minimum, } \\
\text { maximum }\end{array}$ \\
\hline Age (years) & $29 \cdot 5$ & $8 \cdot 7$ & 18,56 \\
\hline Body weight (kg) & $61 \cdot 1$ & $13 \cdot 6$ & $33.4,118.5$ \\
\hline Height (cm) & $164 \cdot 6$ & $5 \cdot 7$ & $152 \cdot 2,180 \cdot 4$ \\
\hline BMI $\left(\mathrm{kg} / \mathrm{m}^{2}\right)$ & 22.5 & 4.6 & $12 \cdot 7,42 \cdot 7$ \\
\hline Relative leg length & 0.49 & 0.02 & $0.40,0.53$ \\
\hline Mid-upper arm circumference (cm) & $27 \cdot 8$ & 4.5 & $19 \cdot 4,41.4$ \\
\hline Waist circumference $(\mathrm{cm})$ & $71 \cdot 1$ & $9 \cdot 8$ & $53.4,110 \cdot 7$ \\
\hline Hip circumference (cm) & $97 \cdot 5$ & $10 \cdot 2$ & $72 \cdot 1,131 \cdot 0$ \\
\hline Waist:hip ratio & 0.728 & 0.047 & $0.633,0.902$ \\
\hline Biceps skinfold (mm) & $7 \cdot 8$ & $5 \cdot 0$ & $1 \cdot 8,26 \cdot 0$ \\
\hline Triceps skinfold (mm) & $17 \cdot 9$ & $7 \cdot 2$ & $5 \cdot 0,35 \cdot 0$ \\
\hline Subscapular skinfold (mm) & $15 \cdot 5$ & 8.5 & $3 \cdot 7,40 \cdot 0$ \\
\hline Suprailiac skinfold (mm) & $14 \cdot 6$ & $7 \cdot 2$ & $3 \cdot 6,36 \cdot 0$ \\
\hline Sum of the four skinfolds (mm) & $55 \cdot 8$ & $25 \cdot 3$ & $16 \cdot 0,118 \cdot 7$ \\
\hline Skinfold ratio* & $1 \cdot 18$ & 0.31 & $0.54,2 \cdot 10$ \\
\hline
\end{tabular}

Table 1. Characteristics of the 196 Senegalese women (Mean values and standard deviations)

* (Sum of subscapular + suprailiac)/(sum of triceps + biceps $)$. 
Table 2. Body density, body fat percentage (\%BF) and fat-free mass (FFM) measured by air-displacement plethysmography (ADP) and body density predicted from skinfold thickness by using the equation of Durnin \& Womersley (D\&W) and transformed in \%BF or FFM by using the equation of Siri or the black-specific equation, in the 196 Senegalese women

(Mean values and standard deviations)

\begin{tabular}{|c|c|c|c|}
\hline & Mean & SD & Minimum, maximum \\
\hline \multicolumn{4}{|l|}{ ADP } \\
\hline Body density ADP $\left(\mathrm{kg} / \mathrm{cm}^{3}\right)$ & 1.0261 & 0.0198 & $0.9784,1.0796$ \\
\hline \multicolumn{4}{|l|}{ Black-specific equation } \\
\hline$\% \mathrm{BF}_{\mathrm{ADP}}$ & $34 \cdot 3$ & $9 \cdot 1$ & $10 \cdot 7,57 \cdot 2$ \\
\hline $\mathrm{FFM}_{\mathrm{ADP}}(\mathrm{kg})$ & $39 \cdot 1$ & 4.6 & $28 \cdot 1,52 \cdot 0$ \\
\hline \multicolumn{4}{|l|}{ Skinfold thickness } \\
\hline \multicolumn{4}{|l|}{ D\&W equation } \\
\hline Body density ${ }_{D W}\left(\mathrm{~kg} / \mathrm{cm}^{3}\right)$ & $1.0361^{*}$ & 0.0150 & $1.0080,1.0735$ \\
\hline \multicolumn{4}{|l|}{ Siri equation } \\
\hline$\% \mathrm{BF}_{\mathrm{DWS}}$ & $27 \cdot 8^{\star}$ & $6 \cdot 9$ & $11 \cdot 1,41 \cdot 1$ \\
\hline FFM $_{\text {DWs }}(\mathrm{kg})$ & $43 \cdot 3^{\star}$ & $6 \cdot 4$ & $29 \cdot 7,71 \cdot 7$ \\
\hline \multicolumn{4}{|l|}{ Black-specific equation } \\
\hline$\% \mathrm{BF}_{\mathrm{DWB}}$ & $29 \cdot 7^{\star}$ & $6 \cdot 8$ & $13 \cdot 3,42 \cdot 6$ \\
\hline $\mathrm{FFM}_{\mathrm{DWB}}(\mathrm{kg})$ & $42 \cdot 2^{\star}$ & $6 \cdot 3$ & $29 \cdot 0,69 \cdot 8$ \\
\hline
\end{tabular}

DWS, Durnin \& Womersley equation coupled with Siri equation; DWB, Durnin \& Womersley equation coupled with black-specific equation.

Mean values were significantly different from the corresponding reference value measured by $\operatorname{ADP}$ (see Table 3 ): ${ }^{*} P<10^{-4}$.

a significant correlation between the difference and the mean in all the comparisons in the whole sample (Table 3), and in the normal BMI except for FFM. We also tested the relationship between the bias and some other anthropometric characteristics of the women (age, relative leg length, waist:hip ratio and SF ratio). Results were the same for $\% \mathrm{BF}_{\mathrm{DWs}}$ and $\% \mathrm{BF}_{\mathrm{DWB}}$, and are given below for $\% \mathrm{BF}_{\mathrm{DWB}}$. The correlations of the bias in $\% \mathrm{BF}$ with the four anthropometric characteristics were not significant in the whole sample, whereas there was a significant correlation with age $(R-0.22 ; P=0.03)$ in the normal BMI class, with relative leg length in the normal $(R 0.26 ; P=0.009)$ and overweight $(R 0.43 ; P=0.003) \mathrm{BMI}$ classes, and with SF ratio $(R-0.35 ; P=0.02)$ in the thin BMI class.

\section{Discussion}

It is necessary to know whether published predictive equations for body composition are usable in Africa, where new equations are likely to be rare. In the present study, we first tested the validity of body density prediction from the measurements of four SF by using the D\&W equation in African women. The intra-subject technical errors we found for the four SF (between 0.4 and $0.6 \mathrm{~mm}$ ) appeared acceptable compared with values reported previously (Harrison et al. 1988). The wide ranges of age, body density, weight, height and SF in the subjects in this study were completely covered by the ranges in the Caucasian sample from which the D\&W equation was derived. The ADP we used as reference is a reliable and valid technique that can quickly and safely evaluate body density (Demerath et al. 2002; Fields et al. 2002). Our reference values were therefore obtained using the same approach (body density measurement based on the twocompartment model) as the one used to develop the D\&W equation as it was validated against HD.

Second, we tested the effect of using a black-specific calculation when transforming the body density into \% BF values, instead of the Siri equation (1961) that was based on constant values for density of body fat and lean mass derived from Caucasians. When taking into account in our sample the newly derived values for the density of fat and lean mass from African-Americans, we obtained a black-specific equation that is consistent with the recommendation made by Heyward (2001). The reference $\% \mathrm{BF}_{\mathrm{ADP}}$ and $\mathrm{FFM}_{\mathrm{ADP}}$ values were obtained from body density ${ }_{\mathrm{ADP}}$ by using the black-specific calculation and, for comparative purposes, the body density ${ }_{\mathrm{DW}}$ obtained from $\mathrm{SF}$ was transformed into \% BF using the two calculations.

\section{Validity of the formulas}

Compared with the ADP method, the D\&W equation significantly overestimated body density by an average of $0.0100 \mathrm{~kg} / \mathrm{cm}^{3}$ in our sample, and the pure error value $\left(0.0143 \mathrm{~kg} / \mathrm{cm}^{3}\right)$ was higher than the standard error of estimate value obtained when establishing the $\mathrm{D} \& \mathrm{~W}$ equation $\left(0.0116 \mathrm{~kg} / \mathrm{cm}^{3}\right)$. As a result of this overestimation of density, predicted \%BF was underestimated, and FFM consequently overestimated. Contrary to our results, an overestimation of \%BF was reported in African-American women (Brandon, 1998). The \% BF underestimation we found is most likely due to the overestimation of body density by the D\&W equation, which was relatively small (1\%) but significant, and yielded a large \%BF bias value even when transformed by using the black-specific calculation. According to the subjective rating system based on standard error of estimate values to appreciate the quality of a prediction equation (Heyward, 2001),

Table 3. Comparison of body density, body fat percentage (\%BF) and fat-free mass (FFM) measured by air-displacement plethysmography (ADP) and body density predicted from skinfold thickness by using the equation of Durnin \& Womersley (DW) and transformed in \%BF or FFM by using the equation of Siri or the black-specific equation, in the 196 Senegalese women

\begin{tabular}{|c|c|c|c|c|c|}
\hline & \multicolumn{2}{|c|}{ Difference } & \multirow[b]{2}{*}{$95 \%$ limits of agreement } & \multirow[b]{2}{*}{ Correlation* $(r)$} & \multirow[b]{2}{*}{ Pure error } \\
\hline & Mean & SD & & & \\
\hline \multicolumn{6}{|l|}{ ADP value minus predicted: } \\
\hline Body density ${ }_{D W}\left(\mathrm{~kg} / \mathrm{cm}^{3}\right)$ & $-0.0100 \dagger$ & 0.0097 & $0.0091,0.0290$ & $0.50 \ddagger$ & 0.014 \\
\hline$\% \mathrm{BF}_{\mathrm{DWS}}$ & $6.5 \dagger$ & 4.5 & $-2 \cdot 3,15 \cdot 3$ & $0.50 \ddagger$ & $7 \cdot 9$ \\
\hline $\mathrm{FFM}_{\mathrm{DWs}}(\mathrm{kg})$ & $-4.3 \dagger$ & 3.5 & $-11 \cdot 2,2 \cdot 5$ & $-0.54 \ddagger$ & 5.5 \\
\hline$\% \mathrm{BF}_{\mathrm{DWB}}$ & $4.6 \dagger$ & 4.5 & $-4 \cdot 2,13 \cdot 4$ & $0.53 \ddagger$ & $6 \cdot 5$ \\
\hline
\end{tabular}

DWS, Durnin \& Womersley equation coupled with Siri equation; DWB, Durnin \& Womersley equation coupled with black-specific equation.

* Between the mean and difference of the two methods.

Mean differences were significant compared with zero: $† P<10^{-4}$.

Correlations were significant: $\ddagger P<10^{-4}$. 
Table 4. Differences in body density, body fat percentage (\%BF) and fat-free mass (FFM) measured by air-displacement plethysmography (ADP) and body density predicted from skinfold thickness by using the equation of Durnin \& Womersley (DW) and transformed in \%BF or FFM by using the equation of Siri or the black-specific equation, by BMI classes in the 196 Senegalese women

(Mean values and standard deviations)

\begin{tabular}{|c|c|c|c|c|c|c|c|c|c|}
\hline & \multicolumn{8}{|c|}{ BMI class } & \multirow[b]{3}{*}{$P$ (between the four groups) } \\
\hline & \multicolumn{2}{|c|}{$<18.5 \mathrm{~kg} / \mathrm{m}^{2}(n 43)$} & \multicolumn{2}{|c|}{$\begin{array}{c}18.5-25.0 \mathrm{~kg} / \mathrm{m}^{2} \\
(n 96)\end{array}$} & \multicolumn{2}{|c|}{$\begin{array}{c}25 \cdot 0-30 \cdot 0 \mathrm{~kg} / \mathrm{m}^{2} \\
(n 46)\end{array}$} & \multicolumn{2}{|c|}{$\geq 30.0 \mathrm{~kg} / \mathrm{m}^{2}(n 11)$} & \\
\hline & Mean & SD & Mean & SD & Mean & SD & Mean & SD & \\
\hline \multicolumn{10}{|l|}{ ADP value minus predicted: } \\
\hline Body density ${ }_{D W}\left(\mathrm{~kg} / \mathrm{cm}^{3}\right)$ & $-0.0051^{*}$ & 0.0082 & $-0.0097^{\star}$ & 0.0099 & $-0.0124^{*}$ & 0.0069 & $-0.0235^{\star}$ & 0.0098 & $<10^{-4}$ \\
\hline FFM $_{\text {DWs }}(\mathrm{kg})$ & $-2 \cdot 0^{*}$ & 1.8 & $-3 \cdot 7^{\star}$ & $2 \cdot 7$ & $-5 \cdot 6^{*}$ & $2 \cdot 6$ & $-12 \cdot 1^{*}$ & $5 \cdot 5$ & $<10^{-4}$ \\
\hline$\% \mathrm{BF}_{\mathrm{DWB}}$ & $2 \cdot 2 \dagger$ & 3.6 & $4 \cdot 4^{*}$ & 4.5 & $5 \cdot 6^{*}$ & $3 \cdot 1$ & $11 \cdot 3^{*}$ & $4 \cdot 8$ & $<10^{-4}$ \\
\hline FFM $_{\text {DWB }}(\mathrm{kg})$ & $-1 \cdot 1 \dagger$ & 1.8 & $-2 \cdot 6^{\star}$ & $2 \cdot 6$ & $-4 \cdot 2^{*}$ & 2.5 & $-10 \cdot 6^{\star}$ & $6 \cdot 2$ & $<10^{-4}$ \\
\hline
\end{tabular}

DWS, Durnin \& Womersley equation coupled with Siri equation; DWB, Durnin \& Womersley equation coupled with black-specific equation.

Mean differences were significant compared with zero: ${ }^{*} P<10^{-4}, \dagger P<10^{-3}$.

all our pure errors can be regarded as very poor, reflecting the lack of validity in our sample of African women. The significant biases in \%BF we observed had higher absolute values than those reported in other non-Caucasian groups, i.e. Chinese (Wang \& Deurenberg, 1996), Indian (Kashiwazaki et al. 1998) and African-American (Zillikens \& Conway, 1990; Brandon, 1998) adults.

In our sample, the biases were dependent on the magnitude of each body composition parameter assessed, and this is confirmed by the fact that the lower the BMI group, the lower was the bias absolute value. The larger \% BF bias values we observed with higher level of body fatness or in the higher BMI groups can be explained by the fact that with increasing body fatness, the ratio of subcutaneous fat to total body fat becomes smaller as shown by Kral et al. (1993) in obese subjects, so that SF underestimate body fatness in subjects with high \%BF (or BMI values). Another explanation could be that, in general, the thicker the skinfold the more difficult it is to achieve a reproducible measurement (Harrison et al. 1988) leading to larger error in measurement in subjects with high \%BF. In addition, at very low body fatness, the thickness of the skin is a relatively large part of the measured skinfold, resulting in a relative overestimation of body fat. This dependency of the bias on the level of body fatness has been observed in many other studies and is a general drawback of many prediction methods.

\section{Reasons for the lack of validity}

When establishing their equation, Durnin \& Womersley (1974) already took into account the differences in distribution of subcutaneous fat with sex and age. However, other factors can affect the accuracy and precision of the D\&W equation (Wong et al. 2000), such as a racial difference in SF (Cronk \& Roche, 1982) or in subcutaneous fat patterning (Norgan, 1995; Malina, 1996), and notably between blacks and whites (Wagner \& Heyward, 2000). In particular, relatively greater fat deposition on the trunk than on the extremities was observed in black females in comparison with white females (Zillikens \& Conway, 1990; Malina, 1996). Moreover, blacks showed more upper-body fat deposition and possibly more deep-body fat deposition than whites (Zillikens \& Conway, 1990). Such observations probably offer an explanation for the lack of validity of the D\&W equation in our sample of African women, as recently suggested in the case of Singaporean subjects (Deurenberg \& Deurenberg-Yap, 2003).

Errors in fat estimates occur when ethnicity is not accounted for (Ortiz et al. 1992; Werkman et al. 2000; Wong et al. 2000; Deurenberg-Yap et al. 2001; Wagner \& Heyward, 2001). When compared with a four-compartment model, Deurenberg-Yap et al. (2001) found in Singaporeans that using densitometry alone and the Siri (1961) equation would have resulted in an underestimation of about $3 \%$ BF. Consequently, the assumption of a constant FFM density leads to systematic large biases in blacks and taking this fact into account, as we did when we used the black-specific calculation, yielded the expected effect of a decrease in the bias value.

The observed bias between SF and ADP methods could also be due to differences in physical characteristics between blacks and whites (i.e. our sample and the $\mathrm{D} \& \mathrm{~W}$ one), and we have to look at their potential effects according to BMI classes. Indeed, our sample included $22 \%$ of thin and $23 \%$ of overweight women, and we could suppose that this fact could influence the results, even if it is not possible to know the proportion of thin or overweight women in the $\mathrm{D} \& \mathrm{~W}$ sample. For example, biological variations in age-related increase in body fatness could be a reason for the lack of validity as there was a significant relationship between the bias in \%BF and age in the normal BMI group, even if the relationship was non-significant in the whole sample. In the same way, the absence of correlation between bias in \%BF and $\mathrm{SF}$ ratio in the whole sample and in the normal BMI subgroup could therefore mean that differences in subcutaneous fat patterning cannot be a reason for the lack of validity in these women. Indeed, the SF ratio in our African women is slightly higher in the whole sample $(1.18)$ but similar in the normal BMI group $(1 \cdot 12)$ compared with the value (approximately $1 \cdot 12)$ we derived for 20-49-year-old women from the original article of Durnin \& Womersley (1974). However, the bias in \%BF was related to the SF ratio in the BMI class of thin women, which had a SF ratio value of $1 \cdot 19$. This relationship could be explained by the fact that thinness is accompanied by a decrease in relative limb fat (i.e. an increase in SF ratio). The SF method makes assumptions in the prediction of \% BF; namely, a constant ratio between \% BF in the arms (from triceps and biceps sites) and trunk (from subscapular and suprailiac sites) compared with the total body, including notably lower limbs. In the present study, the ratio of 
sitting height to height was 0.51 (i.e. relative leg length of 0.49 ), slightly lower than the typical European mean value of 0.52 (Norgan, 1994), indicating that our sample is in fact likely to have a higher value for relative leg length than whites. In our sample, relative leg length was related to the bias in $\% \mathrm{BF}$ in the normal and overweight BMI classes, suggesting that differences in relative leg length could be a reason for the lack of validity except in the case of extreme values (very low or very high) of $\% \mathrm{BF}$ (or $\mathrm{BMI})$.

\section{Conclusion}

The present study confirms the fact that it is unreasonable to use the D\&W equation without adjustment to predict body density in African women. The decrease in bias in \%BF derived from density when using the black-specific calculation showed the need for such a population-specific adjustment. Further development and cross-validation of prediction equations from SF specific to Africans is now needed, as recently done by Deurenberg-Yap et al. (2003) in Singaporean adults and adolescents. Alternatively, for longitudinal or internal comparative purposes, crude values of SF measurements or SF ratio could be used.

\section{Acknowledgements}

We are indebted to the women who agreed to take part in the study.

\section{References}

Biaggi RR, Vollman MW, Nies MA, et al. (1999) Comparison of air-displacement plethysmography with hydrostatic weighing and bioelectrical impedance analysis for the assessment of body composition in healthy adults. Am J Clin Nutr 69, 898-903.

Bland JM \& Altman DG (1986) Statistical methods for assessing agreement between two methods of clinical measurement. Lancet 1, 307-310.

Bland JM \& Altman DG (1995) Comparing methods of measurement: why plotting difference against standard method is misleading. Lancet 346, 1085-1087.

Brandon LJ (1998) Comparison of existing skinfold equations for estimating body fat in African American and white women. Am J Clin Nutr 67, 1155-1161.

Cameron N, Griffiths PL, Wright MM, Blencowe C, Davis NC, Pettifor JM \& Norris SA (2004) Regression equations to estimate percentage body fat in African prepubertal children aged 9 y. Am J Clin Nutr 80, $70-75$.

Cronk CE \& Roche A (1982) Race and sex-specific reference data for triceps and subscapular skinfolds and weight/stature. Am J Clin Nutr 35, 347-354.

Demerath EW, Guo SS, Chumlea WC, Towne B, Roche AF \& Siervogel RM (2002) Comparison of percent body fat estimates using air displacement plethysmography and hydrodensitometry in adults and children. Int J Obes Relat Metab Disord 26, 389-397.

Dempster P \& Aitkens S (1995) A new air displacement method for the determination of human body composition. Med Sci Sports Exerc 27, 1692-1697.

Deurenberg P (1992) The assessment of body composition: uses and misuses. In Annual Report, pp. 35-72. Lausanne: Nestlé Foundation.

Deurenberg P \& Deurenberg-Yap M (2003) Validity of predicted percentage body fat from skinfolds in Singapore Chinese, Malays and Indians. Int J Body Comp Res 1, 23-29.

Deurenberg-Yap M, Ng SA, Foo LL \& Deurenberg P (2003) Development and validation of prediction equation for percentage body fat based on skinfolds for Singaporean adults and adolescents. Int J Body Comp Res 1, 103-109.

Deurenberg-Yap M, Schmidt G, Van Staveren WA, Hautvast JGAJ \& Deurenberg P (2001) Body fat measurement among Singaporean Chinese, Malays and Indians: a comparative study using a four-compartment model and different two-compartment models. Br J Nutr 85, 491-498.

Durnin JVGA \& Womersley J (1974) Body fat assessed from total body density and its estimation from skinfold thickness: measurements on 481 men and women aged from 16 to 72 years. Br J Nutr 32, 77-97.

Fields DA, Goran MI \& McCrory M (2002) Body-composition assessment via air-displacement plethysmography in adults and children: a review. Am J Clin Nutr 75, 453-467.

Gartner A, Dioum A, Delpeuch F, Maire B \& Schutz Y (2004) Use of hand-to-hand impedancemetry to predict body composition of African women as measured by air displacement plethysmography. Eur $J$ Clin Nutr 58, 523-531.

Gartner A, Dioum A, Maire B, Delpeuch F \& Schutz Y (2003) Comparison of foot-to-foot impedance with air-displacement plethysmography to evaluate body composition in African women. Int J Body Compost Res 1, 137-145.

Going SB (1996) Densitometry. In Human Body Composition, pp. 3-23 [AF Roche, SB Heymsfield and TG Lohman, editors]. Champaign, IL: Human Kinetics.

Guo SS, Chumlea WC \& Cockram DB (1996) Use of statistical methods to estimate body composition. Am J Clin Nutr 64, 428S-435S.

Harrison GG, Buskirk ER, Carter JEL, et al. (1988) Skinfold thicknesses and measurement technique. In Anthropometric Standardization Reference Manual, pp. 55-80 [TG Lohman, AF Roche and R Martorell, editors]. Champaign, IL: Human Kinetics.

Heyward V (2001) Methods recommendation: body composition assessment. J Exerc Physiol on line 4, 1-12.

Kashiwazaki H, Dejima Y, Orias RJ \& Coward WA (1998) Validity of published prediction equations for body composition in high altitude Bolivian Aymara as evaluated by doubly labeled water. Am J Hum Biol 10, 371-384.

Kral JG, Mariegos M \& McKeon EW (1993) Body composition studies in severe obesity. In Recent Developments in Body Composition Analysis: Methods and Applications, pp. 137-146 [JG Kral and TB Van Italie, editors]. London, UK: Smith Gordon.

Lohman TG, Roche AF \& Martorell R [editors]. Anthropometric Standardisation Reference Manual. Champaign IL: Human Kinetics.

Lukaski HC (1987) Methods for the assessment of human body composition: traditional and new. Am J Clin Nutr 46, 537-556.

McCrory MA, Gomez TD, Bernauer EM \& Mole PA (1995) Evaluation of a new air displacement plethysmography for measuring human body composition. Med Sci Sports Exerc 27, 1686-1691.

Malina RM (1996) Regional body composition: age, sex, and ethnic variation. In Human Body Composition, pp. 217-253 [AF Roche, SB Heymsfields and TG Lohman, editors]. Champaign, IL: Human Kinetics.

Norgan NG (1994) Relative sitting height and the interpretation of the body mass index. Ann Hum Biol 21, 79-82.

Norgan NG (1995) The assessment of the body composition of populations. In Body Composition Techniques in Health and Disease, pp. 195-221 [PSW Davies and TJ Cole, editors]. Cambridge, UK: Cambridge University Press.

Nunez C, Kovera AJ, Pietrobelli A, et al. (1999) Body composition in children and adults by air displacement plethysmography. Eur J Clin Nutr 53, 382-387.

Oosthuizen GM, Joubert G, Mollentze WF \& Rosslee E (1997) Body fat estimation in black South Africans: a pilot study. Cent Afr J Med 43, 126-131.

Ortiz O, Russell M, Daley TL, et al. (1992) Differences in skeletal muscle and bone mineral mass between black and white females and their relevance to estimates of body composition. Am J Clin Nutr 55, 8-13.

Roche AF, Heymsfield SB \& Lohman TG [editors]. Human Body Composition. Champaign, IL: Human Kinetics.

Siri WE (1961) Body composition from fluid spaces and density: analysis of methods. In Techniques for Measuring Body Composition, 
pp. 223-244 [J Brozek and A Henschel, editors]. Washington, DC: National Academy of Sciences.

Wagner DR \& Heyward VH (2000) Measures of body composition in blacks and whites: a comparative review. Am J Clin Nutr 71, $1392-1402$.

Wagner DR \& Heyward V (2001) Validity of two-component models for estimating body fat of black men. $J$ Appl Physiol 90, 649-656.

Wang J \& Deurenberg P (1996) The validity of predicted body composition in Chinese adults from anthropometry and bioelectrical impedance in comparison with densitometry. Br J Nutr 76, $175-182$.
Werkman A, Deurenberg-Yap M, Schmidt G \& Deurenberg P (2000) A comparison between the composition and density of the fat-free mass of young adult Singaporean Chinese and Dutch Caucasians. Ann Nutr Metab 44, 235-242.

Wong WW, Stuff NF, Butte NF, Smith EOB \& Ellis KJ (2000) Estimating body fat in African American and white adolescent girls: a comparison of skinfold-thickness equations with a 4-compartment criterion model. Am J Clin Nutr 72, 348-354.

Zillikens MC \& Conway JM (1990) Anthropometry in blacks: applicability of generalized skinfold equations and differences in fat patterning between blacks and whites. Am J Clin Nutr 52, 45-51. 